\title{
Kaynak Tabanlı Görüşten Dinamik Yeteneklere Tarihsel Bir İnceleme
}

\begin{abstract}
Kader ŞAHİN ${ }^{1}$
Tuğba KAPLAN ${ }^{2}$

ÖZ: Kaynak Tabanlı Görüş'ün bir uzantısı olarak geliştirilen Dinamik Yetenekler Yaklaşımı işletmelerin zorlu çevre şartlarında nasıl rekabet avantajı elde edeceklerini açıklamaya çalışmaktadır. Dinamik yetenekler yaklaşımının son yıllarda önemi giderek artmakta ve bu alanda farklı bakış açıları ile yapılan çalışmalar karmaşıklık yaratmaktadır. Bu karmaşıklıkları çözmeye uğraşan dinamik yetenekler yaklaşımı ile ilgili ülkemizde yapılan çalışmaların sayısı kısıtlıdır. Bu çalışmanın amacı, kaynak tabanlı görüşten yola çıkan dinamik yetenekler yaklaşımının gelişimini ele alarak dinamik yetenekler yaklaşımının teorik alt yapısını ortaya koymaktır. Kronolojik bir seyirle dinamik yeteneklerin gelişiminin açıklanması, dinamik yeteneklerin gelişimdeki önemli süreçlerin belirlenmesi, son dönem yapılan çalı̧̧malar da kapsayacak bir biçimde özetlenmesi açılarından çalışmanın dinamik yetenekler yaklaşımı ile ilgili yazına katkı săglaması beklenmektedir.
\end{abstract}

Anahtar Kelimeler: Kaynak Tabanlı Görüş, Dinamik Yetenekler, Rekabet Avantaj1

JEL Sinıflaması: L200, L210, L250

\section{A Historical Review from Resource-Based View to Dynamic Capabilities}

\begin{abstract}
Dynamic Capabilities that enhance the Resource Based View tries to explain how firms will gain competitive advantage at difficult environment conditions. The importance of dynamic capabilities is increasing in abroad and in our country, there are limited studies about dynamic studies, which strive to enlighten the complexity of studies that rise from different views. The aim of this study is to reveal theoretical foundations of dynamic capabilities that are based on resource based view throughout investigating the development of dynamic capabilities. The contributions of this study are to explain the development of dynamic capabilities in chronologic order, to specify the important processes in the development of dynamic capabilities, to summarize the studies that include the lastly researches.
\end{abstract}

Keywords: Resource Based View, Dynamic Capabilities, Competitive Advantage

JEL Classification: L200, L210, L250

Geliş Tarihi / Received: 14/06/2017

Kabul Tarihi / Accepted: 22/09/2017

\footnotetext{
${ }^{1}$ Doç. Dr., KTÜ, İİBF, İşletme Bölümü, kadertan@ktu.edu.tr, orcid.org/0000-0003-2957-1854.

2 Arş. Gör., KTÜ, SBE, İşletme Bölümü, t.kaplan@ktu.edu.tr, orcid.org/0000-0003-2880-816X
} 


\section{Giriş}

Uluslararasılaşma ve bu süreci hızlandıran küreselleşme, işletmeler açısından hem yeni fırsatlar hem de tehditlere zemin hazırlamıştır. Hızla değişen yeni firsat ve tehditler ile karşılaşan işletmelerin bu firsat ve tehditleri rekabet avantajına dönüştürerek sürdürülebilir kılması ise işletmelerin varlık sebebi açısından hayatidir. İşletmeler ancak doğru stratejiler uygulayarak sürdürülebilir rekabet avantajı elde edebilmektedir (Duygulu ve Eroğluer, 2006). İşletmelerin nasıl sürdürülebilir rekabet avantajı geliştireceklerini açıklamaya çalışan tutarlı bir çerçeve olarak öne sürülen (Augier ve Teece, 2007) ve "Kaynak Tabanlı Görüş"ün uzantısı olarak geliştirilen "Dinamik Yetenekler"e (Teece vd., 1997) yönelik çalışmaların sayısı son yıllarda gittikçe artmaktadır (Eriksson, 2013).

Teece ve diğerlerinin (1997) Strategic Management Journal'da yayınlanan "Dinamik Yetenekler ve Stratejik Yönetim" adlı makalesi ile stratejik yönetim alanında dikkat çeken dinamik yetenekler, özellikle dinamik/çalkantılı çevre koşullarında işletmelerin rekabet avantajı kazanabilmeleri ve bu avantajı sürdürebilir kılabilmeleri için dinamik yetenekler geliştirmeleri gerektiğini iddia etmektedir (Teece vd., 1997: 509). Bu iddia, pek çok stratejik yönetim araştırmacısının üzerinde durduğu dinamik yeteneklere yönelik ilgiyi arttırırken, kavrama farklı bakış açılarının da dâhil olmasını sağlamıştır (Peteraf vd., 2013: 1390-1394). Literatürde var olan pek çok çalışmanın yarattığı karmaşıklığa ek olarak dinamik yetenekler ile ilgili ülkemizde yapılan çalışmaların sayısı oldukça kisitlidir.

$\mathrm{Bu}$ çalışmanın amacı, kaynak tabanlı görüşten yola çıkan dinamik yetenekler yaklaşımının gelişimini ve teorik alt yapısını ortaya koymaktır. Kronolojik bir seyirle dinamik yeteneklerin gelişiminin açıklanması, dinamik yeteneklerin gelişimdeki önemli süreçlerin belirlenmesi, son dönem yapılan çalışmaları da kapsayacak bir biçimde özetlenmesi açılarından çalışmanın dinamik yetenekler yaklaşımı ile ilgili yazına katkı sağlaması beklenmektedir. Çalışmada dinamik yeteneklerin evrimsel süreci tarihsel bir seyir şeklinde sunulmaktadır. Bu tarihsel seyir içerisinde dinamik yeteneklerin gelişimi üç önemli kırılma noktasına sahip olduğu için çalışma temel olarak üç döneme ayrılmıştır.

Dinamik yeteneklerin ilk dönemi, Penrose'un 1959 çalışması ile başlayan ve 1991 yılındaki Barney'in katkıları ile geliştirilen kaynak tabanlı görüş oluşturmaktadır. Özellikle stratejik bakışı, firmanın içine ve kaynak tabanına çeviren kaynak tabanlı görüş işletmelerin sahip olduğu dinamik yetenekleri anlamamızda büyük öneme sahiptir. $\mathrm{Bu}$ nedenle, çalışmanın ilk bölümünde dinamik yetenekler yaklaşımının çıkış noktası olan kaynak tabanlı görüş ile ilgili temel çalışmalara yönelik bilgi verilerek ve kaynak tabanlı görüşe yöneltilen eleştiriler sunulacaktır. Dinamik yeteneklerin gelişiminde ikinci dönem, dinamik yeteneklerin öne sürüldüğü y1l olan 1994 (Teece ve Pisano, 1994) y1lı ile dinamik yetenekleri farklı bir biçimde ele alan Eisenhardt ve Martin'in 2000 yılındaki çalışmasına dek geçen dönem olarak belirlenmiştir. Kaynak tabanlı görüşün bir uzantısı olarak dinamik 
yetenekler Teece ve Pisano (1994) ile Teece ve diğerlerinin (1997) öncü çalışmaları ile şekillenmeye başlamıştır. İkinci bölümde ise dinamik çevre koşullarını açıklamakta daha başarılı olduğu öne sürülen dinamik yetenekler yaklaşımının tarihsel seyri ele alınacaktır. Dinamik yeteneklerin gelişiminde üçüncü dönem ise, Eisenhardt ve Martin (2000) "Dinamik Yetenekler: Onlar neler?" adlı makalesinin yayınlandığ 2000 yılından 2016 yılına kadar devam eden süreç olarak belirlenmiştir. 2000 yılına dek daha çok Teece ve Pisano (1994) ile Teece ve diğerlerinin (1997) öncülüğünde gelişen dinamik yeteneklere; (Peteraf vd., 2013: 1392) Eisenhardt ve Martin (2000) farklı bir yol ayrımı getirmiştir. Bu noktadan sonra dinamik yetenekler alanında en çok atıf alan (Peteraf vd., 2013) iki çalışma Teece ve diğerlerinin (1997) çalışması ile Eisenhardt ve Martin'in (2000) çalışması olmuştur. Hatta dinamik yetenekler alanındaki bu ayrım birleştirilme ve bütünleştirilme çabalarına konu olmuştur (Peteraf vd., 2013). Çalışmanın üçüncü bölümde ise bu ayrım dikkate alınarak dinamik yetenekler yaklaşımının 2000 yılından günümüze gelişimi açıklanacak ve dinamik yetenekler ile ilgili ampirik çalışmalar değerlendirilecektir. Son olarak, dinamik yetenekler alanında mevcut olan tartışmalar aktarılarak sonuç ve önerilere yer verilecektir.

\section{Kaynak Tabanlı Görüş - 1959'dan 1991'e}

Stratejik yönetim çerçevesinde, kaynak tabanlı yaklaşım esas olarak, ekonomist Edith Penrose'un (1959) "Firma Büyüme Teorisi" çalışmasına dayanmaktadır. Penrose (1959) çalışmasında firmaları homojen girişimler olarak kabul edildiği klasik iktisadi teoriyi sorgulamaktadır. Bu sorgulama sonucunda da firmayı, algılanan firsatların kullanılması ile büyüyen, maddi ve maddi olmayan kaynakların bir birleşimi olan idari yapı olarak tanımlamaktadır. Penrose'a (1959) göre, bir firmanın büyümesini sağlayan rekabet avantajı, o firmanın sahip olduğu kaynaklarından yapılandırılması ile doğrudan ilişkili bir şekilde gerçekleşmektedir (Penrose, 1959: 217). Klasik iktisadi teoriden farklı olarak Penrose'un (1959) çalışmasının ana noktasını, yönetimin deneyiminin üretim hizmetlerini etkileyeceği görüşü ve yönetimin bu kritik rolünün tespit edilmesi oluşturmaktadır. Firmanın yöneticilerinin firma kaynakları ve firmanın faaliyet gösterdiği rekabetçi çevre hakkında izlenimleri, bu yöneticilerin çevredeki değişiklikleri eşsiz üretim firsatlarına dönüştürmesini sağlayabilmektedir. Diğer bir ifadeyle, firma kaynaklarının verimli çıtılara dönüşme sürecinde yöneticiler sahip oldukları yetenekler ile katalizör görevi görmektedir (Penrose, 1959: 5). Yetenek kavramı, bir firmanın ya da yöneticilerinin firma ve çevresi ile arasındaki uyumun geliştirilmesi için tekrar tekrar başlatılan ve uygulanan örgütsel değişim yeteneğini içermektedir (Nelson ve Winter, 1982).

Şekil 1: Kaynak Tabanlı Görüşün Temelleri

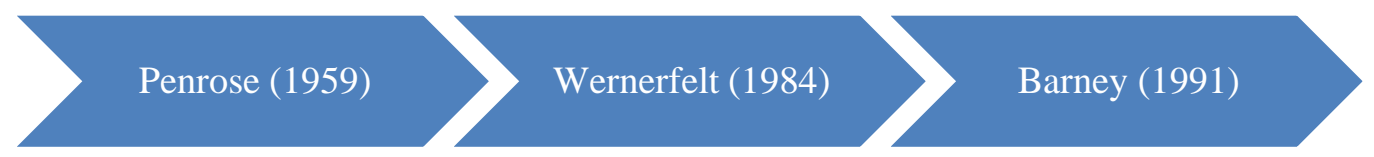


Rekabette başarının içsel yanına dair önemli bir diğer çalışma ise, Penrose'un (1959) çalışmasından 25 yıl sonra Birger Wernerfelt (1984) tarafindan yapılmıştır. Wernerfelt (1984); stratejik yönetimin geleneksel yaklaşımlarından farklılaşan Penrose'un çalışmasını, firmaların oluşumunda kaynakların etkisini incelerken kullanmıştır (Wernerfelt, 1984). "Firmanın Kaynak Tabanlı Görüşü" isimli makalesinde Wernerfelt (1984) bir kaynak ürün matrisi önererek, firmaların kaynak avantajları ile sıralı (sequential) bir şekilde büyüyebileceğini öne sürmüştür. Wernerfelt'e (1984) göre firmaların sahip olduğu kaynakların genişletilmesi ya da yenilerinin geliştirilmesi arasındaki dengeyi ayarlamak oldukça önemlidir ve bu bir ustalık stratejisidir. Bu ustalık stratejisini doğru şekilde yönetebilen firmalar başarılı olabilecektir. Wernerfelt (1995) yaklaşık on yıl sonra yazdığı bir diğer makalesinde 1987'ye kadar sadece üç atıf alan çalışmasının, Prahaland ve Hamel'in (1990) Harvard Business Review'daki makalesinden sonra dikkat çektiğini öne sürmüştür. Wernelfelt'e (1995) göre kendisinin 1984 çalışmasının ilgi görmez iken Prahaland ve Hamel'in (1990) çalışmasının bu denli ilgi görmesindeki temel neden ise daha sonraki çalışmalarının farklı olmasıdır.

Kaynak tabanlı görüşe önemli bir katkı da "Firma Kaynakları ve Sürdürülebilir Rekabet Avantajı" isimli çalışmasıyla Barney (1991) tarafından yapılmıştır. Barney'e (1991) göre, bir firmanın sürdürülebilir rekabet avantajı sağlayabilmesi için gerekli olan kaynaklar değerli, nadir, ikamesi olmayan ve taklit edilemeyen nitelikte olmalıdır. Bu bağlamda, sürdürülebilir rekabet avantajı, var olan ya da potansiyel rakipler tarafindan gerçekleştirilemeyecek ve diğer firmalar tarafindan çoğaltılmayacak olan stratejiyi yaratmak ve uygulamaktır (Barney, 1991: 102). Firmaların benzer kaynakları farklı bir biçimde kullanma eğiliminde olduğunu iddia eden Penrose'un (1959) aksine, Barney (1991); bir firmanın verimliliğini ve etkinliğini arttırmayı sağlayacak olan stratejileri geliştirmek için nadir kaynakların gerekli olduğunu öne sürmüştür. Kaynaklar, yaygın bir biçimde var olmadığında, nadir olarak kabul edilmektedir. Barney'e (1991) göre, firmanın sahip olduğu kaynak, değerli ve nadir olsa bile rakip firmalar tarafından taklit edilebilir olduğunda sürdürülebilir rekabet avantajından söz edilmeyecektir. Benzer bir şekilde, bir kaynağın kullanılması ile elde edilen sonuçlar, stratejik olarak eşdeğer başka bir kaynağın kullanılması ile elde edilebiliyorsa, yani kaynağın ikamesi mevcutsa bu durumda da rekabet avantajı sürdürülebilir olmayacaktır (Barney, 1991).

Barney'in (1991) çalışmasının totolojik olduğunu öne süren Priem ve Butler'e (2001) göre sürdürülebilir rekabet avantajını rakipler tarafından gerçekleştirilemeyecek stratejiyi yaratmak ve uygulamak olarak tanımladığınızda bu zaten bilinen bir gerçektir. Dolayısıyla deneysel olarak test edilmesine bile gerek kalmayan bu ifade totolojik duruma düşmektedir. Ayrıca Priem ve Butler (2001) kaynak tabanlı görüşün bir teori olmaktan uzak olduğunu, hatta Barney'in (1991) teorinin temel varsayımlarının pek de farkında olmadığını belirtmiştir. Buna ek olarak Priem ve Butler (2001) kaynak tabanlı görüşü statik olmakla 
suçlamakta ve stratejik yönetim için tek başına kullanışlı bir araç olmadığını öne sürmektedir. Barney (2001) ise gelen bu eleştirilere karşı çıkarak, aslında Priem ve Butler'ın (2001) kendisinin kaynak tabanlı görüş ile ilgili çalışmasını çok anlamadıklarını, eleştirdikleri bazı konuları daha önceki çalışmalarında zaten açıklamış olduğunu belirtmiştir. Barney (2001), kaynak tabanlı görüş ile ilgili savlarının totolojik olmadığını ve farklı alanlardaki kaynak tabanlı teoriler (yapıyönetim-performans/SCP, neo-klasik mikro iktisat ve evrimsel iktisat) ile birlikte kullanışlı bir araç olduğunu iddia etmektedir.

Kaynak tabanlı görüşe eleştiri oklarını yönelten bir diğer isim olan Grant'a (1991) göre de kaynak tabanlı görüşün bazı kısıtları da bulunmaktadır. Bunlardan ilki, firma yöneticilerinin firma kaynaklarını doğru bir biçimde belirleyerek sınıflandırdığı varsayımıdır. Ayrıca firma yöneticilerinin rakiplerine oranla daha değerli olan mevcut ya da potansiyel kaynakları analiz edebildiği kabul edilmektedir. Firma yöneticilerinin, fırsatlara uygun bir biçimde firma kaynaklarını en iyi kullanacak stratejiyi geliştirebileceği öne sürülmektedir. Kaynak tabanlı görüşe ait tüm bu varsayımların, özellikle hızlı ve tahmin edilemeyen değişimin bulunduğu çevresel koşullarda gerçekleşmesi mümkün olmamaktadır (Eisenhardt ve Martin, 2000; Grant, 1991; Teece vd., 1997). Belirsizliğin öne çıktığı iletişim, teknoloji gibi dinamik pazarlarda kaynak tabanlı görüş yetersiz kalmaktadır (Teece vd., 1997; Teece, 2003). Newbert'e (2007) göre, bir firmanın sadece eşsiz kaynaklara sahip olması, özellikle çalkantılı çevrelerde, o firmanın başarılı olmasını ya da rekabet avantajı elde etmesini sağlamayacaktır (Newbert 2007: 136). Wang ve Ahmed (2007: 33-34) ise, kaynak tabanlı görüş ile ilgili çalışmalarda kaynakların, süreçlerin ve kabiliyetlerin ele alınmasına ilişkin terminolojilerin tanım eksiklikleri olduğunu öne sürmektedir. Ayrıca, kaynak tabanlı görüş, statik yapısından dolayı dinamik pazarlarda sürdürülebilir rekabet avantajının kaynağı olamamakta ve kaynakların rekabet avantajına dönüşmesi ile ilgili süreçleri net olarak açıklayamamaktadır. Kaynak tabanlı görüşün bu eksikliklerini gidermeye çalışan daha dinamik bir yaklaşım olan ve Eisenhardt ve Martin'in (2000) çalışmasına dek Teece ve diğerlerinin (1997) öncü çalışması ışı̆̆ında şekillenen dinamik yetenekler yaklaşımı ortaya çıkmaktadır (Wang ve Ahmed, 2007).

\section{Dinamik Yetenekler - 1994'den 2000'e}

Kaynak tabanlı görüşe rekabetçi bir çevrede firmanın başarısının, firmanın kaynaklarına bağımlı olduğu kabul edilmektedir. Buna rağmen, yüksek oranda değişimin olduğu pazar koşullarında firmanın kaynakları sadece geçici rekabet avantajını açıklayabilecektir (Eisenhardt ve Martin, 2000). İşte bu noktadan hareketle, Teece ve diğerleri (1997); konunun odağını firmanın kaynak yapılandırmasından alarak, çevresel koşullara göre kaynak yapılandırmalarını tanımlayan öncül strateji ve rutinlere kaydırmaktadır. Teece ve diğerleri (1997) bu öncül strateji ve rutinleri, firmanın dinamik yetenekleri olarak adlandırmaktadır (Teece ve Pisano, 1994; Teece vd., 1997). Dinamik yetenekler yaklaşımının 
1997'de stratejik yönetim literatürüne girmesinden bu yana, dinamik yeteneklere duyulan ilgi giderek artmış ve çok sayıda çalışma yapılmıştır (Örn: Teece vd., 1997; Eisenhardt ve Martin, 2000; Winter, 2003; Helfat ve Peteraf, 2003; Teece, 2007; Pitelis ve Teece, 2010; Pavlou ve Sawy, 2011; Rodenbach ve Brettel, 2012; Eriksson vd., 2013; Peteraf vd., 2013; Ramirez vd., 2013; Schilke, 2013).

Dinamik yetenekler yaklaşımın tanımı, unsurları üzerinde bir fikir birliği bulunmamaktadır (Peteraf vd., 2013: 1390-1394). Dinamik yeteneklerin ilk tanımına baktığımızda, Teece ve Pisano (1994) dinamik yetenekleri; firmanın yeni ürünler ve süreçler yaratmasını ve değişen çevre şartlarına cevap vermesini sağlayan kabiliyetler toplamı olarak tanımlamıştır. Teece (1997), bir diğer çalışmasında dinamik yetenekleri, hızla değișen çevre koşullarına cevap verebilmek için, firmanın, iç ve dıș yeterlilikleri bütünleștirme, inşa etme ve yeniden yapılandırma kabiliyeti olarak açıklamaktadır (Teece vd., 1997: 516). Zollo ve Winter (1999) ise dinamik yetenekleri verimliliğin arttırılması için, örgütsel rutinler oluşturma, geliştirme yolu ile öğrenilmiş ortak faaliyet örüntüleri şeklinde ifade etmektedir.

Dinamik kavramı, yetkinliliklerin yenilenmesi ve değişen çevre koşullarına uyum sağlama yeteneğini ifade etmektedir. Collis (1994:150), yeteneklerin, sürekli olarak üretimini ilerleterek, firmanın ürün pazar performansının sürekli bir şekilde geliştirmesini sağlayarak, dinamik olmaları gerektiğini öne sürmektedir. Teece ve diğerleri (1997: 515) ise, dinamik kavramını, değişen iş çevresine cevap verilebilmesi için yetkinliklerin yenilenmesi yeteneği olarak ifade etmektedir. Bu noktada, zamanlamanın kritik olduğu pazara sürme zamanında, teknolojik değişim oranının hızlı olduğu ve gelecek rekabetin yoğun olduğu ve pazar yapısının tanımlanmasının zor olduğu durumlarda, bazı yenilikçi yanıtlar gerekmektedir.

Yetenek terimi değişen çevre koşullarının gereksinimlerini karşılamak için, iç ve dış örgütsel kabiliyetlerin, kaynakların ve işlevsel yetkinliklerin uygun bir şekilde adapte edilmesi, bütünleştirilmesi ve yeniden yapılandırılmasında, stratejik yönetimin kilit rolünü ifade etmektedir (Teece vd., 1997: 515). Yetenekler bireysel beceriden oluşmamaktadır. Aksine, yetenekler, bireysel yeteneklerin mozaiği üzerindeki bağlantılardan kaynaklanan örgütsel elemanlar olmaktadır. $\mathrm{Bu}$ bağlantılar, firma kaynakları arasında uzun vadeli dönemlerde ve çok yönlü etkileşimler süresince gelişmiş olan örgüt ürünleri olarak kabul edilmektedir (Amit ve Schoemaker, 1993). Bu nedenle, yetenekler, sadece görünür kurumsal yapı ve süreçlerinde mevcut olmayıp, firmaların örgüt kültürlerinde de bulunmaktadır (Collis, 1994).

Dinamik yeteneklere yönelik yapılan çalışmalar incelendiğinde 2000 yılına dek, Teece ve Pisano (1994) ile Teece ve diğerlerinin (1997) öncü çalışmaları 1şığında dinamik yeteneklerin yeni bir stratejik yaklaşım olarak ortaya konulabilmesi ve geliştirilmesine yönelik çalışmaların olduğu görülecektir (Teece ve Pisano,1994; Teece vd., 1997; Helfat,1997; Zollo ve Winter, 1999). Diğer bir ifadeyle, bu dönem yapılan çalışmaların sayısı nispeten az olsa da çoğunlukla dinamik 
yeteneklere teorik bir zemin hazırlamaya yönelik çalışmalardan oluşmaktadır. Eisenhardt ve Martin'in (2000) çalışması ise bu teorik altyapının yeniden kurgulanması gerektiğini öne süren, dinamik yeteneklerin varlığını kabul eden ama bu yetenekler için öne sürülen koşulların yeniden tanımlanması gerektiğini iddia eden bir çalıșma olmuştur. Bu çalıșma ile beraber dinamik yetenekler iki farklı dalda ilerlerken Peteraf ve diğerlerinin (2013) yapmış olduğu gibi çeşitli bütünleştirme çabaları da görülmüştür.

\section{Dinamik Yetenekler - 2000'den 2016'ya}

Dinamik yetenekler kavramı incelendiğinde kronolojik olarak farklılaşan ve atıf alma sayısı ile ön plana çıkan (Peteraf vd., 2013: 1392) Teece ve diğerlerine (1997) ve Eisenhardt ve Martin'e (2000) ait iki yaklaşım ortaya çıkmaktadır. Her iki yaklaşım da dinamik yetenekler yaklaşımı ele alış biçimleri açısından, öne sürdükleri varsayımlar açısından, teorik alt yapıları ve önerdikleri sonuçlar açısından birbirinden farklılaşmaktadır (Peteraf vd., 2013). Teece ve diğerlerinin (1997) çalışması ile Eisenhardt ve Martin (2000) tarafından yapılan çalışmaların farklılıkları bir sonraki sayfada yer alan Tablo 1'de verilmiştir.

Tablo 1: Teece ve diğerleri (1997) ile Teece (2007) ve Eisenhardt ve Martin (2000)

\begin{tabular}{|c|c|c|}
\hline Konu & ri (1997) & isenhardt ve Martin (2000) \\
\hline $\begin{array}{l}\text { Dinamik } \\
\text { Yetenekler } \\
\text { Tanımı }\end{array}$ & $\begin{array}{l}\text { Hızla değişen çevre koşullarına } \\
\text { cevap verebilmek için, firmanın, } \\
\text { iç ve dış yeterlilikleri } \\
\text { bütünleştirme, inşa etme ve } \\
\text { yeniden yapılandırma kabiliyeti }\end{array}$ & $\begin{array}{l}\text { Kabiliyetler değil, pazarda değişime } \\
\text { cevap vermek, hatta değişim yaratmak } \\
\text { için gereken yöneticilerin kaynak } \\
\text { tabanını değisstirmesi, ürün yenilemesi } \\
\text { gibi özel örgütsel ve stratejik süreçler }\end{array}$ \\
\hline $\begin{array}{l}\text { Dinamik } \\
\text { Yeteneklerin } \\
\text { Odağı }\end{array}$ & $\begin{array}{l}\text { Daha çok yüksek teknolojik } \\
\text { değişimin olduğu çevrelerle ilgili }\end{array}$ & $\begin{array}{l}\text { Daha çok yüksek teknolojik değişimin } \\
\text { olduğu çevrelerdeki kısıtlar ile ilgili }\end{array}$ \\
\hline $\begin{array}{l}\text { Dinamik } \\
\text { Yeteneklerin } \\
\text { Oluşumu }\end{array}$ & $\begin{array}{l}\text { Detayli analitik rutinlere } \\
\text { dayanmakta }\end{array}$ & $\begin{array}{l}\text { Analitik rutinlerin yerini pazar } \\
\text { dinamizmine bağ }{ }_{11} \text { olarak denenmiş } \\
\text { basit rutinler almakta }\end{array}$ \\
\hline $\begin{array}{l}\text { Dina } \\
\text { Yete } \\
\text { Geliş }\end{array}$ & $\begin{array}{l}\text { Dinamik yeteneklerin gelişimi } \\
\text { açısından klasik görüş, eşsiz } \\
\text { rotadan bahsederken }\end{array}$ & $\begin{array}{l}\text { Yeni görüş, uygulama, kodlama, hata } \\
\text { yapma ve adımlama biçiminde ortaya } \\
\text { çıan öğrenme sistemleri tarafindan } \\
\text { şekillenen eşsiz rotayı öne sürmektedir }\end{array}$ \\
\hline $\begin{array}{l}\text { Rek } \\
\text { Ava }\end{array}$ & $\begin{array}{l}\text { Değerli, eşsiz, taklit edilemeyen } \\
\text { ve ikamesi olmayan dinamik } \\
\text { yetenekler sayesinde belirli } \\
\text { koşullar altında sürdürülebilir } \\
\text { rekabet avantaj1 }\end{array}$ & $\begin{array}{l}\text { İkamesi bulunan, değerli, kısmen } \\
\text { nadir, karşıllğ̆ olan, aynı sonucu veren } \\
\text { dinamik yetenekler sonucu her türlü } \\
\text { koşul altında sadece sinırlı bir düzeyde } \\
\text { sürdürülebilir rekabet avantaj1 }\end{array}$ \\
\hline $\begin{array}{l}\text { Dinamik } \\
\text { Yeteneklerin } \\
\text { Çıktıları }\end{array}$ & hmin edilebilir & $\begin{array}{l}\text { Çıttılar pazar dinamizmine bağl1 } \\
\text { olarak tahmin } \\
\text { edilemeyebilir }\end{array}$ \\
\hline
\end{tabular}

Kaynak: Peteraf ve diğerlerinden (2013) uyarlanmıştır. 
Teece ve diğerlerinin (1997) çalıșması ile Eisenhardt ve Martin (2000) tarafindan yapılan çalışmalardan farklı olarak Tablo 2'de görüleceği üzere, dinamik yetenekler alanında pek çok tanımlama da bulunmasına rağmen bunlar genellikle yetenekler ve süreçler üzerinde ayrılmaktadır. Kavramsal açıdan bu tanımlamaların çoğu anlamlı, fakat işlevsel olarak, literatürde yer alan bu tanımlamalardan dinamik bir yeteneği yerine oturmak neredeyse imkânsız olmaktadır (Peteraf vd., 2013).

Tablo 2: Dinamik Yetenek Tanımları

\begin{tabular}{|l|l|}
\hline \multicolumn{1}{|c|}{$\begin{array}{c}\text { Yetenek/Kabiliyet Olarak Tanımlayan } \\
\text { Çaşsmalar }\end{array}$} & \multicolumn{1}{c|}{$\begin{array}{c}\text { Faaliyet/Süreç Olarak Tanımlayan } \\
\text { Çalş̧malar }\end{array}$} \\
\hline Luo (2000) & \\
\hline Griffith ve Harvey (2001) & \\
\hline Zahra ve George (2002) & Zollo ve Winter (2002) \\
\hline & Helfat ve Peteraf (2003) \\
\hline & Winter (2003) \\
\hline Zahra vd. (2006) & \\
\hline & Helfat vd. (2007) \\
\hline & Schreyögg ve Kliesch-Eberl (2007) \\
\hline Wang ve Ahmed (2007) & \\
\hline Teece (2007) & \\
\hline Chen ve Jaw (2009) & \\
\hline Wu (2010) & \\
\hline Ellonen vd. (2011) & \\
\hline Gebauer (2011) & \\
\hline Hodgkinson ve Healey (2011) & \\
\hline Pavlou ve Sawy (2011) & \\
\hline Protogerou vd. (2011) & \\
\hline Woldesenbet vd. (2011) & Leung (2012) \\
\hline Jantunen vd. (2012) & \\
\hline & \\
\hline & \\
\hline Rodenbach ve Brettel (2012) & \\
\hline Piening (2013) & \\
\hline Schilke (2013) & \\
\hline Wilden vd. (2013) & \\
\hline Sanirez vd. (2013) \\
\hline
\end{tabular}

Kaynak: Yazar tarafından hazırlanmıştır. 
Dinamik yetenekler ile ilgili tanımlar incelendiğinde, bu tanımlar dinamik yeteneklerin ne olduğunu anlattığı gibi ne olmadığını da ortaya koymaktadır. İlk olarak; dinamik yetenekler, olağan bir tepki ya da bir olaya yönelik problem çözme tekniği değildir. Dinamik yetenekler daha çok bir rota takip eden, tekrarlanır eylemler içermektedir (Helfat vd., 2007; Schreyögg ve Kliesch-Eberl, 2007; Winter, 2003). İkinci olarak, dinamik yeteneklerde şans faktörü yer almamaktadır çünkü dinamik yetenekler belirli bir amaç doğrultusunda istenilerek oluşturulmaktadır (Helfat vd., 2007; Zahra vd., 2006). Ayrıca dinamik yetenekler stratejik değişim ile ilgili olmasına rağmen stratejik değişim ile eşanlamlı değildir. Diğer bir ifadeyle, dinamik yetenekler tek başına stratejik değişim yaratmamakta, dinamik yeteneklerdeki değişim daha çok kaynak tabanının değişimini ifade etmektedir (Ambrosini ve Bowman, 2009).

Dinamik yetenekler yaklaşımına yönelik olarak ülkemizde yapılan çalışmaların sayısı oldukça kısıtlıdır. İlk olarak, bir blogta Süslüoğlu tarafından yapılan, işletmelerde çekirdek teknolojilerle dinamik yeteneklerin arasındaki işbirliğinin değerlendirilmesine yönelik bir çalışma bulunmaktadır. Bu çalışma, ampirik bir çalışma olmayıp, dinamik yetenekler literatürü ile ilgili kısa bir sunuş niteliğinde hazırlanmıştır (Süslüoğlu, 2012). Bir diğer çalışmada (Acar ve Zehir, 2008) dinamik yetenekler kavramı, kaynak tabanlı işletme yetenekleri olarak ele alınmıştır. Çalışmada, İstanbul'daki orta ve büyük işletme yöneticilerine yönelik anket çalışması yapılarak; kaynak tabanlı işletme yeteneklerinin, globalleşme yeteneği, pazarlama ve satış yetenekleri, üretim yetenekleri, lojistik yetenekler, yönetim yetenekleri, bilgi sistemleri yeteneği, öğrenme yeteneği ve ortaklık kurma yeteneği olmak üzere yedi boyutlu olduğu öne sürülmüştür (Acar ve Zehir, 2008).

Dinamik bir yetenek olarak teknoloji yönetimi yeteneğinin incelendiği bir diğer çalışma (Ünsal, 2009) ise, dinamik yetenekler yaklaşımı ile teknoloji yönetimi kavramının geliştirildiği teorik bir çalışmadır. Dinamik yetenekler yaklaşımına ilişsin bir başka çalışma da kısa bir sunuş niteliğinde gerçekleşmiştir (Yamen, 2010). Dinamik yetenekler alanında ülkemizde yapılmış olan ampirik bir çalışmada (Gümüşoğlu, 2012) ise, farklı iş stratejileri doğrultusunda dinamik yeteneklerin yeni ürün geliştirme performansı üzerindeki etkileri incelenmiştir. 203 firmadan alınan anket sonuçları neticesinde; sezme yeteneğinin yenilikçi, analizci ve savunmacı strateji izleyen firmaları pozitif etkilediği, yakalama yeteneğinin, yenilikçi ve analizci strateji izleyen firmaları pozitif etkilediği, yeniden düzenleme yeteneğinin ise sadece analizci strateji izleyen firmaları pozitif etkilediği tespit edilmiştir. Son olarak, Şahin ve diğerleri (2015) tarafından yapılan bir çalışmada, işletme grupları perspektifinde global dinamik yeteneklerin uluslararasılaşma sürecinde kullanımı analiz edilmiştir. Araştırma kapsamında, Türkiye'deki 19 çokuluslu işletme grubu, işletme kaynakları, küresel dinamik yetenekler, çevresel belirsizlik, uluslararasılaşma, giriş ve lokasyon stratejileri bağlamında incelenmiştir. Araştırma sonucunda, küresel dinamik yeteneklerin 
işletmelerin uluslararasılaşma süreçlerinde etkili olduğu iddia edilmektedir (Şahin vd., 2015).

Son dönemde yapılmış olan bir çalışmaya (Eriksson, 2013) göre; 1991 ve 2009 yılları arasında, dinamik yetenekler alanında yapılmış olan 373 çalışmanın 232'si ampirik olarak gerçekleşmiştir. Geriye kalan teorik çalışmalar ise dinamik yeteneklerin tanitılması (Teece vd., 1997; Eisenhardt ve Martin 2000; Zahra vd., 2006; Teece, 2007; Wang ve Ahmed, 2007), dinamik yetenekler yaklaşımının geliştirilmesi (Zahra ve George, 2002; Helfat ve Peteraf, 2003; Winter, 2003; Schreyögg ve K.-Eberl, 2007; Duh, 2013; Gomez ve Ballard, 2013), dinamik yeteneklerin öncülleri (Ahen, 2014), dinamik yetenekler yazınındaki eksiklikler (Ambrosini ve Bowman, 2009; Arend, 2015), dinamik yetenekler yazınındaki karmaşıklığın giderilmesi (Arndt ve Bach, 2015; Barreto, 2010; Beske vd., 2014; Makadok, 2001), uluslararası işletmecilik (Luo, 2000; Augier ve Teece, 2007; Pitelis ve Teece, 2010) ve davranışsal boyutu (Hodgkinson ve Healey, 2011; Teece, 2012; Kor ve Mesko, 2013) üzerinde yoğunlaşmaktadır. Ampirik çalışmalar içerisinde ise; dinamik yetenekler ile doğrudan ilgili olan 142 çalışmanın, 67'si öncüllere, 64'ü süreçlere ve 45'i çıktılara yönelik olarak hazırlanmıştır. Doğrudan dinamik yetenekler ile ilgili olan bu çalışmaların yarısında nitel yöntemler, \%41'inde nicel yöntemler kullanılmış iken, sadece \%8'inde her ikisini de içeren karışık yöntemlere yer verilmiştir. Aynı dönem çalışmaların örnek kütleleri ise, \%12'si tek firma, \%19'u iki ile on firma, \%36's1 on firmadan daha fazla, \%27'si 100 firmadan daha az ve \%6's1 100 firmadan daha fazla olarak siralanmaktadır (Eriksson, 2013: 1-16).

Dinamik yetenekler literatürü incelendiğinde, ampirik çalışmalar, dinamik yeteneklerin öncülleri, süreçler ve çıktıları açısından farklılaşmaktadır. Dinamik yeteneklerin öncülleri yani dinamik yetenekler üzerinde etkili olan faktörler, süreçleri yani dinamik yeteneklerin öncülleri ve çıtılarının firmadaki süreçleri ve çıktıları yani dinamik yeteneklerin etkilediği sonuçlar açısından 2000 ve 2016 yılları arasında dinamik yetenekler alanında yapılmış bazı ampirik çalışmalar Tablo 3'te sunulmuştur.

Çalışmalarda en sık görülen dinamik yetenekler öncülleri yani dinamik yetenekler üzerinde etkili olan faktörler, içsel ve dişsal olarak ikiye ayrılmaktadır (Eriksson, 2013). İçsel faktörler, örgüt yapısı (Narayanan vd., 2009), kaynak dağılımı, çalışan kabiliyetleri (Ravishankar ve Pan, 2013; Rodenbach ve Brettel, 2012) gibi yapısal unsurlar ile örgütsel konumlama (Zhou ve Li, 2010), yönetsel konumlama (Ramirez vd., 2013), örgütsel kabiliyetler (Capron ve Mitchell, 2009) ve örgütsel uygulamalar (Parente vd., 2011) şeklinde çalışılmıştır. Dışsal faktörler ise, kurumsallaşma (Piening, 2013), pazar (Arafa ve Elmaraghy, 2011), teknoloji gibi çevresel faktörler (Leung, 2012) ile iletişim ağı konumu (Cabanelas vd., 2013), varlık düzeni (Blome vd., 2013), ortaklardan öğrenme gibi iletişim ve ilişki (Jiao vd., 2013) faktörlerinden meydana gelmektedir. 
Tablo 3: Dinamik Yetenekler ile İlgili Ampirik Çalışmalar (2000-2016)

\begin{tabular}{|c|c|}
\hline 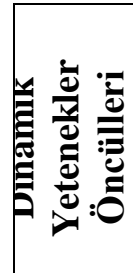 & $\begin{array}{c}\text { Griffith ve Harvey (2001), Kay (2007), Capron ve Mitchell (2009), Narayanan } \\
\text { vd.(2009), Zhou ve Li (2010), Arafa ve Elmaraghy(2011), Parente vd. (2011), } \\
\text { Leung (2012), Rodenbach ve Brettel (2012), Cabanelas vd.(2013), Piening } \\
\text { (2013), Ramirez vd. (2013), Ravishankar ve Pan (2013), Dixon vd. (2014), } \\
\text { Lecler ve Kinghorn (2014), Darmani (2015), D.Driesch vd. (2015), Lee } \\
\text { vd.(2015), Macpherson vd. (2015) }\end{array}$ \\
\hline & $\begin{array}{l}\text { Rindova ve Kotha (2001), Borch ve Madsen (2007), Wu (2007), Chen ve Jaw } \\
\text { (2009), Russo (2009), Chiou (2011), Drnevich ve Kriauciunas (2011), Ellonen } \\
\text { vd. (2011), Kim vd. (2011), Pavlou ve Sawy (2011), Protogerou vd. (2011), } \\
\text { Woldesenbet vd. (2011), Arend (2012), Huang vd. (2012), Li ve Liu (2012), } \\
\text { Makkonen vd. (2012), Yusr vd. (2012), Jiao vd. (2013), Jones vd. (2013), } \\
\text { Kindström vd. (2013), Schilke (2013), Wilden vd. (2013), Yung (2013), Zhan } \\
\text { ve Chen (2013), Chien ve Syue (2014), Ciutiene ve Thattakath (2014), Galvin } \\
\text { vd. (2014), Feiler ve Teece (2014), Naldi vd. (2014), Oliver (2014), Olufemi } \\
\text { vd. (2014), Schilke (2014), Vanpoucke vd. (2014), El Akremi vd. (2015), } \\
\text { Karım ve Walter (2015), Leonidou vd. (2015), Lin vd. (2015), Masteika ve } \\
\text { Čepinskis (2015), Rice vd. (2015), Wilden ve Gudergan (2015), Wilhelm vd. } \\
\text { (2015), Aminu ve Mahmood (2016), Lin vd. (2016), Pezeshkan vd. (2016), } \\
\text { Takahashi vd. (2016) }\end{array}$ \\
\hline 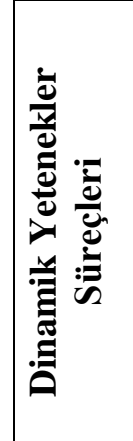 & $\begin{array}{l}\text { Lawcon ve Samson (2001), Eggers (2006), Wu (2010), Gebauer (2011), Iris ve } \\
\text { Vikas (2011), Salunke vd. (2011), Ali vd. (2012), Jantunen vd. (2012), Newey } \\
\text { vd. (2012), Wu ve Hu (2012), Yung ve Lai (2012), Blome vd. (2013), Denford } \\
\text { (2013), Eriksson vd. (2013), Arena vd. (2014), Chatteji ve Patro (2014), Daniel } \\
\text { vd. (2014), D.Stefano vd. (2014), Lin ve Ma (2014), Sicotte vd. (2014), Wu vd. } \\
\text { (2014), Aminu ve Mahmood (2015), B.Molina vd. (2015), Bohl (2015), } \\
\text { Bingham vd. (2015), Butler ve Soontiens (2015), Chang vd. (2015), Dentoni } \\
\text { vd. (2015), Dohen vd. (2015), Janssen vd. (2015), Wang vd. (2015), } \\
\text { Weerawardena vd. (2015), Eltantawy (2016), Finch vd. (2016), Hermano ve } \\
\text { M.Cruz (2016) }\end{array}$ \\
\hline
\end{tabular}

Kaynak: Eriksson (2013)'ten esinlenilerek hazırlanmıştır.

Dinamik yeteneklere ilişkin en sık çalışılan süreçler ise, bilgi birikimi oluşturma (Iris ve Vikas, 2011; Wu, 2010), bilgi birikimini bütünleştirme (Ali vd., 2012), bilgi birikimini kullanma ( $\mathrm{Wu}$ ve $\mathrm{Hu}, 2012$ ) ve bilgi birikimini yeniden yapılandırma (Denford, 2013) veya dinamik yetenekler öncülleri ve çıtılarının firmadaki süreçleri (Breznik ve Lahovnik, 2014; Lin ve Ma, 2014; Yung ve Lai, 2012) şeklinde olmaktadır. Son olarak, dinamik yeteneklerin çıktılarına baktığımızda ise, yapılan çalışmalarda, rekabet avantajı (Li ve Liu, 2012), ekonomik performans (Makkonen vd., 2012; Protogerou vd., 2011; Wilden vd., 2013; Yung, 2013), yaratıc1 ya da teknolojik performans (Ellonen vd., 2011; Wu, 2007), çevresel performans (Huang vd., 2012; Russo, 2009) ve içsel performans (Chen ve Jaw, 2009; Kim vd., 2011) en çok çalış1lan konular olmaktadır. 


\section{Tartışma}

Farklı bakış açılarına sahip stratejik yönetim araştırmacılarının, dinamik yetenekler yaklaşımına ilgileri giderek artmaktadır. Bu bakış açılarındaki farklılık nedeniyle, yaklaşımın tanımı, unsurları ve ölçüm yöntemlerinde de bir fikir birliği bulunmamaktadır (Arend ve Bromiley, 2009). Dinamik yetenekler yaklaşımı, firmaların nasıl rekabet avantajı geliştireceklerini ve bunu sürdürülebilir rekabet avantajına çevirmek için ne yapacaklarını açıklamaya çalışan tutarlı bir çerçeve oluşturmaya çalışmaktadır (Augier ve Teece, 2007: 179).

Teece ve diğerlerine (1997) göre dinamik yeteneklerin var olması için hızla değişen çevre koşullarına ihtiyaç duyulmaktadır (Teece vd., 1997). Teece ve diğerlerinin (1997) bu yaklaşımına karşıt bazı çalışmalara göre dinamik yeteneğin varlığı ile çevresel dinamizm ayrı tutulmalıdır (Eisenhardt ve Martin, 2000; Zahra vd., 2006; Zollo ve Winter, 2002). Zahra ve diğerleri (2006), esasen farklı olan bu yaklaşımı, literatürde var olan büyük bir karışıklık kaynağı olarak görmektedir. Dinamik yetenekler, firmanın değişen çevre koşullarını yakalamasını ve uyum sağlamasını amaçlamaktadır (Teece vd. 1997; Helfat vd., 2007). Böylelikle, dinamik yetenekler firmanın var olan yeteneklerini köhne bir hale getirme yönünde kendisini tehdit eden çevresel dinamizm ile nasıl mücadele edeceğini ele almaktadır (Winter, 2003). Dinamik yeteneklerin çekirdeğinde olan çevresel dinamizm, dinamik yeteneklerin gelişimi için ihtiyaç duyulan itici güç olarak kabul edilmektedir (Wang ve Ahmed, 2007).

Zahra ve diğerleri (2006) yapmış oldukları çalışmada, literatürdeki bazı araştırmaların, firmaların sahip olduğu dinamik yetenekleri firma başarısı ile birleştirilmesi eğiliminde oldukları sonucuna ulaşmıştır. Bu bağlamda, başarısız firmaların herhangi bir dinamik yeteneğinin olmadığı anlamına geleceğinden, Zahra ve diğerleri (2006), bu anlayışı yetersiz ve totolojik olarak kabul etmektedir. Teece ve diğerleri (1997) dinamik yeteneklerin rekabet avantajına katkıda bulunduğunu ileri sürerken (Teece, 2007), kimi çalışmalarda dinamik yetenekler ve firma performansı arasında bir ilişki bulunamamıştır. Hatta bazı çalışmalarda, dinamik yetenekler için katlanılan maliyetler neticesinde firma ekonomik performansına negatif etkide bulunduğu tespit edilmiştir (Eriksson, 2013). Diğer bir görüşe göre dinamik yetenekler doğrudan firmanın performansına veya rekabet avantajına katkıda bulunmamakta bunun yerine firmanın kaynaklarını ustalıkla idare etmesine izin vermektedir (Helfat vd., 2007). Dinamik yetenekler, rakip firmalardan daha çabuk, etkili ve rastlantısal uygulandığında rekabet avantajının kaynağı olmaktadır (Eisenhardt ve Martin, 2000: 1117; Wang ve Ahmed, 2007).

Dinamik yeteneklerin geçici problem çözme yöntemi olarak görülüp görülmemesi gerektiğine dair de literatürde tartışmalar bulunmaktadır (Winter, 2003: 992). Winter (2003), dinamik yeteneklerin sadece rota bağımlılığ üzerinden değil, öngörülmeyen çevresel dinamizme de cevap vermesi gerektiğini öne sürmüştür. Dinamik yeteneklerin şirketler için doğrudan rekabetçi avantaj 
yaratıp yaratmadığı konusunda birçok tartışma olduğu görülmektedir. Dinamik yeteneklerin, firma performansı ile sürdürülebilir rekabetçi avantajı sağlamak için var olan kaynaklarına bağlı kalmaktan vazgeçerek, kaynaklarını yeniden düzenlenmesine kolayca izin vermesi görüşü, tartışma konusu olmaya devam etmektedir (Helfat vd., 2007).

Dinamik yetenekler yaklaşımına getirilen bazı eleştiriler arasında, dinamik yeteneklerin tutarlı bir tanımının olmaması ve ölçüm zorluğu bulunmaktadır (Pavlou ve Sawy, 2011). Arend ve Bromiley (2009), bu eksiklikler sonucunda dinamik yeteneklerin terk edilmesi gerektiğini iddia etmektedir. Başlıca iddialarından ilki, dinamik yetenekler yaklaşımı çalışmalarının, absorbe edici kapasite, stratejik uyum, pazara ilk giren olma avantaj1, örgütsel öğrenme ve değişim yönetimine ait önceki çalışmaları yeniden beyan etmekten başka bir şey yapmadıklarıdır. Dolayısıyla, dinamik yeteneklerin, bu çalışmaların ötesinde bir değer eklemeleri ve inandırıcı bir yaklaşım olarak kabul edilebilmesi için, bir temele sahip olması gerekmektedir. Dinamik yeteneklerin ikinci bir eleştirisi, literatürdeki tutarsız tanımlar nedeniyle ortaya çıkmaktadır. Bu, dinamik yetenekler üzerine kitap yazanlar da dâhil olmak üzere, birçok araştırmacı tarafından paylaşılan bir görüştür (Arend ve Bromiley, 2009; Collis, 1994; Winter, 2003). Üstelik dinamik yetenekler neticesinde firma performansının arttığı öne sürülürken, dinamik yeteneklerin oluşumu için katlanılan maliyetler de göz ardı edilebilmektedir (Peteraf vd., 2013).

Dinamik yetenekler yaklaşımına getirilen bir diğer eleştiri de, dinamik yeteneklerin kesin ampirik desteklerden yoksun olması yönünde gerçekleşmektedir (Rodenbach ve Brettel, 2012: 612). Dinamik yeteneklere yönelik çalışmalarda az miktarda ampirik destek, zaman içerisindeki gelişmeyi görmek için yeterli olmayan nicel çalışmalardan gelmektedir. Arend ve Bromiley (2009), ampirik desteklerin çoğunun dinamik yeteneklere sahip başarılı firmaları bulan araştırmalardan geldiği gerçeğini de ortaya koymaktadır. Ek olarak, dinamik yeteneklerin ölçülmesi için pek çok farklı ölçüm metodu olsa da genel olarak kabul edilebilir, üzerinde fikir birliğine varılan bir ölçüm yöntemi bulunmamaktadır. Üstelik dinamik yeteneklere yönelik çalışmaların iş dünyasına yönelik pratik uygulama ve faydaları yetersiz düzeyde kalmaktadır (Arend ve Bromiley, 2009).

Belirtilen eksikliklerine karşılık dinamik yetenekler yaklaşımının halen emekleme düzeyinde olduğu öne sürülmektedir (Teece, 2007; Helfat vd., 2007). Arend ve Bromiley'in (2009) eleştirilerinin bazı haklı tarafları olmasına rağmen, yazarlar, dinamik yetenekler yaklaşımının tamamını göz önünde bulundurmamakta ve teorinin genç bir teori olduğunu düşünmemektedirler. Helfat ve Peteraf (2009), dinamik yetenekler yaklaşımının, kavramsal düzeyden gelişmeye başlayan, ortadan kaldırılacak bazı konuları içeren genç bir teori olduğunu göstermektedirler. Araştırmacılar aynı zamanda, zayıf bir ampirik destek olduğu iddiasını da reddetmekte, birçok güçlü ampirik çalışmayı örnek göstermekte ve 
gençliği yüzünden, dinamik yeteneklerin kurulu bir ampirik çalışma zeminine sahip olmasının beklenmemesi gerektiğini ifade etmektedirler (Helfat ve Peteraf, 2009).

Öne sürülen tüm eleştirilere rağmen, dinamik yetenekler yaklaşımı teorik dayanaklara sahiptir. Bu teorik dayanaklardan ilki, nedensellik olarak kabul edilmektedir. Örneğin, birçok çalışma, dinamik yeteneklerin bir firmaya daha fazla yaratıcı yetenek kazandırmasına nasıl sebep olacağını göstermektedir (Eisenhardt ve Martin, 2000). Ayrıca, dinamik yetenekler, yeni ürün geliştirilmesi, patentler ve öğrenme çıktıları aracılığı ile ölçülebilmektedir (Zollo ve Winter, 2002). Dinamik yetenekler yaklaşımı belirsizlik şartları altında gücünü göstermiştir. Bazı çalışmalar, firmaların, öğrenme yetenekleri ile hızla değişen çevrelerle daha iyi başa çıkabileceklerini öngörmüştür. Dahası, dinamik yeteneklerin tahrif edilebilecek teorik bir niteliğe sahip olduğunu gösteren çalışmaların doğru olmadığı ispatlanmıştır (Zollo ve Winter, 2002).

Dinamik yetenekler yaklaşımı, teorik dayanaklara sahip olmasına rağmen, olgunlaşma aşamasına henüz ulaşmamış ve özellikle küçük girişimler olmak üzere, küçük firmalar için tanımlanmış önlem ve yapılardan yoksun olmaktadır. Yönetimde mükemmel bir teori olmadığı gibi dinamik yetenekler yaklaşımı da mükemmel değildir. Eleştirilerin çoğu geçerli olsa da, gelecekte bunları ele alacak araştırmalar için gerekli potansiyele sahiptir. Ayrıca, dinamik yetenekler yaklaşımı, hızla değişen çevre koşullarının nedenini düzgün bir şekilde açıklayan az miktardaki yaklaşımdan biri olarak kabul edilmektedir (Eisenhardt ve Martin, 2000; Teece vd., 1997; Winter, 2003).

\section{Sonuç ve Öneriler}

Kaynak tabanlı görüşten yola çıkan dinamik yetenekler yaklaşımının gelişimini ele alarak dinamik yetenekler yaklaşımının teorik alt yapısını ortaya koymak amacıyla yapılan bu çalışmada dinamik yeteneklerin gelişimi kronolojik bir seyirle sunulmuştur. Bu bağlamda Penrose'un 1959 çalışması ile başlayan ve 1991 yılındaki Barney'in katkıları ile geliştirilen kaynak tabanlı görüş dönemi çalışmanın birinci dönemi olarak açıklanmıştır. Dinamik yeteneklerin öne sürüldügü yıl olan 1994 (Teece ve Pisano, 1994) yılı ile dinamik yetenekleri farklı bir biçimde ele alan Eisenhardt ve Martin'in 2000 yılındaki çalışmasına dek geçen süreç ikinci dönem olarak aktarılmıştır. Son olarak dinamik yeteneklerin Eisenhardt ve Martin (2000) ve Teece ve diğerleri (1997) tarafindan yapılan çalışmaların yarattığı ayrımdan günümüze dek geçen zaman dinamik yeteneklerin gelişimindeki üçüncü dönem kabul edilmiştir. Gerçekten de kaynak tabanlı görüşün statik yapısına karşılık dinamik çevre koşullarını da dikkate alan dinamik yetenekler yaklaşımı ile ilgili yapılan pek çok çalışma bu ayrım doğrultusunda şekillenmiştir. Dolayısıyla çalışmanın birinci amacı olan dinamik yetenekler kavramının teorik alt yapısının ortaya konulmasında üç dönemde ele alınması literatürdeki incelemelerle desteklenmiştir. Dinamik yetenekler literatürü incelendiğinde dinamik yetenekleri faaliyet/süreç olarak tanımlayan çalışmalara 
kıyasla yetenek/kabiliyet olarak tanımlayan çalışmaların daha ağırlıklı olduğu görülmektedir. Bunun en önemli nedenlerinden birisinin kaynak tabanlı görüşü statik olmakla eleştiren dinamik yetenekler yaklaşımının faaliyet/süreç gibi statik hale gelebilecek kavramlardan uzaklaşması olarak görülebilecektir. Ayrıca bu alandaki yazına davranışsal bakış açılarının da dâhil olması ile beraber, özellikle üst düzey yöneticilerin dinamik yetenekler alanındaki önemine yönelik yapılan çalışmaların daha çok yetenek/kabiliyet ekseninde gerçekleştiği söylenebilir. Dinamik yeteneklerin gelişiminde ikinci dönem olarak belirlenen 2000 yilından sonra yapılan ampirik çalışmaların dinamik yeteneklerin çıktıları, dinamik yeteneklerin süreçleri ve dinamik yeteneklerin öncülleri şeklinde sıralandığ ortaya çıkmaktadır. Buradan hareketle dinamik yetenekler alanının oluşumu için yapılan teorik desteklerin zamanla yerini daha çok ampirik testlere bıraktığ söylenebilir.

Dinamik yetenekler yaklaşımı son yıllarda önemi giderek artmış ve farklı bakış açılarının yarattığı karmaşıklığı gidermeye uğraşan çeşitli literatür taraması çalışmaları yapılmıştır (Eriksson, 2013; Peteraf vd., 2013; Piening, 2013; Wang ve Ahmed, 2007). Uluslararasılaşma ve rekabet avantajı elde etme firma stratejilerinde yeni arayışlara yönelimi sağlamış. Bu çerçevede kaynak tabanlı görüşün yerinde firmaların dinamik yeteneklere yoğunlaşması gerektiğine ilişkin tartışmalar artmıştır. Bu tartışmalar, dinamik yetenekler alanındaki literatürün gelişmesine ve beraberinde firmaların zorlu çevre koşullarında rekabet avantajı elde etme çabalarının da artmasına neden olmuştur. Fakat dinamik yetenekler alanındaki literatürün nispeten yeni gelişiyor olması ve özellikle de ülkemizde halen yeterince ilgi görmemesi ülkemizdeki firmaların uluslararasılaşması ve bu yönde strateji geliştirebilmelerinin de yetersizliği olarak karşımıza çıkmaktadır. Bu bağlamda bu çalışmanın kronolojik bir seyirle dinamik yeteneklerin gelişimini açıklaması, dinamik yeteneklerin gelişimdeki önemli süreçleri belirlemesi ve son dönem yapılan çalışmaları da kapsayacak bir biçimde dinamik yeteneklerin dönemselleştirilmesi açılarından dinamik yetenekler yaklaşımı ile ilgili yazına katk1 sağlaması beklenmektedir. Stratejik yönetim alanının nispeten yeni sayılabilecek olan dinamik yetenekler yaklaşımı ile ilgili olarak ülkemizde yapılacak çalışmaların sayısının arttırılması gerekmektedir. Özellikle ülkemiz gibi çevresel dinamizmin ve belirsizliklerin yoğun olduğu çevre şartlarında faaliyet gösteren işletmeler dinamik yetenekler geliştirdikleri takdirde daha başarılı olabileceklerdir. Diğer bir ifadeyle dinamik yetenekleri olan bu işletmeler kazandıkları rekabet avantajını bu sayede sürdürülebilir rekabet avantajına dönüştürebileceklerdir. Özellikle dinamik yeteneklerin uygulamada nasıl şekillendiğinin ortaya çıkarılabilmesi adına uygulamaya yönelik yapılacak çalışmaları stratejik yönetim alanın gelişmesine önemli katkılar sağlayacaktır. 


\section{Kaynakça}

Acar, Z. A. ve Zehir, C. (2008), "Kaynak Tabanlı İşletme Yetenekleri Ölçeği Geliştirilmesi ve Doğrulanması”, Dokuz Eylül Üniversitesi Iş̧letme Fakültesi Dergisi, 8(1), 103-131.

Ahen, F. (2014), "Ethically Constrained Optimization of Dynamic Capabilities: Towards Sustainable Global Health", Social Responsibility Journal, 10(3), 436 $-454$.

Akremi A. E., Perrigot, R. ve Piot-Lepetit I. (2015), "Examining the Drivers for Franchised Chains Performance through the Lens of the Dynamic Capabilities Approach", 53 (1), 145-165.

Ali, S., Peters, L. D. ve Lettice, F. (2012), "An Organizational Learning Perspective on Conceptualizing Dynamic and Substantive Capabilities", Journal of Strategic Management, 20(7), 589-607.

Ambrosini, V. ve Bowman, C. (2009), "What are Dynamic Capabilities and are They a Useful Construct in Strategic Management", International Journal of Management Reviews, 11 (1), 29-49.

Aminu, I. A. ve Mahmood R. (2015), "Mediating Role of Dynamic Capabilities on the Relationship between Intellectual Capital and Performance: A Hierarchical Component Model Perspective in PLS-SEM Path Modeling", Research Journal of Business Management, 9(3), 443-456.

Aminu, I. A. ve Mahmood R. (2016), "Modeling Dynamic Capabilities in their Logical Squence and Relation to Performance", The Social Sciences, 11(2), 106-112.

Amit, R. ve Schoemaker, P. (1993), "Strategic Assets and Organisational Rent", Strategic Management Journal, 14(1), 33-46.

Arafa, A. ve Elmaraghy W. (2011), "Manufacturing Strategy and Enterprise Dynamic Capability", CIRP Annals - Manufacturing Technology, 60, 507-510.

Arena M., Azzone G., Cagno E., Silvestri A. ve Trucco P. (2014), "A Model for Operationalizing ERM in Project-Based Operations Through Dynamic Capabilities", International Journal of Energy Sector Management, 8(2), 178 197.

Arend, R. J. ve Bromiley, P. (2009), "Assessing the Dynamic Capabilities View: Spare Change, Everyone?", Strategic Organization, 7(1), 75-90.

Arend, R. J. (2012), "Entrepreneurship and Dynamic Capabilities: How Firm Age and Size Affect the Capability Enhancement-SME Performance Relationship", Small Business Economics, 42(1), 33-57.

Arend, R. J. (2015), "Mobius' Edge: Infinite Regress in the Resource-Based and Dynamic Capabilities Views", Strategic Organization, 13(1), 75-85. 
Arndt, F. ve Bach N. (2015), "Evolutionary and Ecological Conceptualization of Dynamic Capabilities: Identifying Elements of the Teece and Eisenhardt Schools", Journal of Management \&Organization, 21(5), pp 701-704.

Augier, M. ve Teece, D. (2007), "Dynamic Capabilities and Multinational Enterprise: Penrosean Insights and Omissions", Management International Review, 47(2), 175-192.

Barney, J. (1991), "Firm Resources and Sustained Competitive Advantage", Journal of Management, 17(1), 99-120.

Barney, J. (2001), "Is the Resource-Based View a Useful Perspective for Strategic Management Research? Yes", Academy of Management Review, 26(1), 41-56.

Barreto, I. (2010), "Dynamic Capabilities: A Review of Past Research and an Agenda for the Future", Journal of Management, 36(1), 256-280.

Beske, P., Land A. ve Seuring S. (2014), "Sustainable Supply Chain Management Practices and Dynamic Capabilities in the Food Industry: A Critical Analysis of the Literature", International Journal of Production Economics, 152, 131143.

Bingham, C. B., Heimeriks K. H., Schijven M. ve Gates S. (2015), "Concurrent Learning: How Firms Develop Multiple Dynamic Capabilities in Parallel", Strategic Management Journal, 36, 1802-1825.

Blome, C., Schoenherr, T. ve Rexhausen, D. (2013), “Antecedents and Enablers of Supply Chain Agility and Its Effect on Performance: A Dynamic Capabilities Perspective", International Journal of Production Research, 51(4), 1295-1318.

B. Molina, V., Montes F. J. L. ve G. Gutierrez L. J. (2015),"Dynamic Capabilities, Human Resources and Operating Routines", Industrial Management \& Data Systems, 115(8), 1388 - 1411.

Bohl, P. (2015), "Dynamic Capabilities and Strategic Paradox: A Case Study", Studies and Articles, 11, 25-38.

Borch, O. J. ve Madsen, E. L. (2007), "Dynamic Capabilities Facilitating Innovative Strategies in SMEs", International Journal of Technoentrepreneurship, 1(1), 109-125.

Butler, B. ve Soontiens W. (2015), "Offshoring of Higher Education Services in Strategic Nets: A Dynamic Capabilities Perspective", Journal of World Business, 50, 477-490.

Cabanelas, P., Cabanelas, J. O. ve Vázquez, X. H. (2013), “A Methodology for the Construction of Dynamic Capabilities in Industrial Networks: The Role of Border Agents", Industrial Marketing Management, 42(6), 1-12. 
Capron, L. ve Mitchell, W. (2009), "Selection Capability: How Capability Gaps and Internal Social Frictions Affect Internal and External Strategic Renewal", Organization Science, 20(2), 294-312.

Chang, K. H., Chen, Y. R. ve Huang H. F. (2015), "Information Technology and Partnership Dynamic Capabilities in International Subcontracting Relationships", International Business Review, 24, 276-286.

Chatteji, A.ve Patro A. (2014), "Dynamic Capabilities And Managing Human Capital", The Academy of Management Perspectives, 28(4), 395-408.

Chen, C.ve Jaw, Y. (2009), "Building Global Dynamic Capabilities through Innovation: A Case Study of Taiwan's Cultural Organizations", Journal of Engineering and Technology Management, 26, 247-263.

Chien T. K. ve Syue J. C. (2014), "Which Dynamic Capabilities Needed for Successfully Promoting ERP Activity?", in IEEE International Conference on e-Business Engineering, 1694-1698.

Chiou, C. H. (2011), "Dynamic Capabilities, Collaborative Network and Business Model: An Empirical Analysis of Taiwan HTC Corporation", African Journal of Business Management, 5 (2), 294-305.

Ciutiene, R. ve Thattakath, E. W. (2014), "Influence of Dynamic Capabilities in Creating Disruptive Innovation", Economics and Business, 26, 15-21.

Collis, D. (1994), "How Valuable are Organizational Capabilities?", Strategic Management Journal, 15 (1), 143-152.

Daniel, E. M., Ward J. M. ve Franken A. (2014), "A Dynamic Capabilities Perspective of IS Project Portfolio Management", Journal of Strategic Information Systems, 23, 95-111.

Darmani, A. (2015), "Renewable Energy Investors in Sweden: A Cross-Subsector Analysis of Dynamic Capabilities", Utilities Policy, 37, 46-57.

Driesch, T. V. D., Costa, M. E. S. D., Flatten T. C. ve Brettel M. (2015), "How CEO Experience, Personality, and Network Affect Firms' Dynamic Capabilities", European Management Journal, 33, 245-256.

Denford, J. S. (2013), "Building Knowledge: Developing a Knowledge-based Dynamic Capabilities", Journal of Knowledge Management, 17 (2), 175-194.

Dentoni, D., Bitzer, V. ve Pascucci S. (2015), "Cross-Sector Partnerships and the Co-creation of Dynamic Capabilities for Stakeholder Orientation", Journal of Business Ethics, 1-19.

Dixon S., Meyer, K. ve Day M. (2014), "Building Dynamic Capabilities of Adaptation and Innovation: A Study of Micro-Foundations in a Transition Economy", Long Range Planning, 47, 186-205. 
Dohen, M. S., Gale N. ve Tan J. (2015), "Healthcare Informatics Competencies as Microfoundations of Dynamic Capabilities: Theory Development and Methodological Considerations", in 48th Hawaii International Conference on System Sciences, 2853-2863.

Drnevich, P. L. ve Kriauciunas, A. P. (2011), "Clarifying the Conditions and Limits of the Contributions of Ordinary and Dynamic Capabilities to Relative Firm Performance", Strategic Management Journal, 32, 254-279.

Duh, M. (2013), "Toward More Operational Dynamic Capabilities Concept: Possible Contribution of the Dynamic Enterprise Construct" International Journal of Business and Management, 8 (9), 24-33.

Duygulu, E. ve Eroğluer, K. (2006), "Örgüt Kültürünün Çalışanların İş Doyumuna Etkisi: Bir Firma Uyguluması", Dokuz Eylül Üniversitesi IIIBF Dergisi, 21 (2), $1-21$.

Eggers, J. P. (2006), "Customizing Dynamic Capabities: Learning, Adapting and Focusing in Product Portfolio Management", Academy of Management Conference, 1-6.

Eisenhardt, K. ve Martin, J. (2000), "Dynamic Capabilities: What are They?", Strategic Management Journal, 21, 1105-1121.

Ellonen, H., Jantunen, A., ve Kuivalainen O. (2011), "The Role of Dynamic Capabilities in Developing Innovation Related Capabilities", International Journal of Innovation Management, 15 (3), 459-478.

Eltantawy, R. A. (2016), "The Role of Supply Management Resilience in Attaining Ambidexterity: A Dynamic Capabilities Approach", Journal of Business \& Industrial Marketing, 31 (1), 123 - 134.

Eriksson, T. (2013), "Processes, Antecedents and Outcomes of Dynamic Capabilities", Scandinavian Journal of Management, 30 (1), 65-82.

Eriksson, T., Nummela, N. ve Saarenketo S. (2013), "Dynamic Capability in a Small Global Factory", International Business Review, 23 (1), 169-180.

Feiler P. ve Teece D. (2014), "Case Study, Dynamic Capabilities and Upstream Strategy: Supermajor EXP", Energy Strategy Reviews, 3, 14-20.

David, J. F., Peacock M., Levallet N. ve Foster W. (2016),"A Dynamic Capabilities View of Employability", Education + Training, 58 (1), 61-81.

Galvin, P., Rice, J. ve Liao, T. S. (2014), "Applying a Darwinian Model to the Dynamic Capabilities View: Insights and Issues", Journal of Management \& Organization, 20, 250-263.

Gebauer, H. (2011), "Exploring the Contribution of Management Innovation to the Evolution of Dynamic Capabilities", Industrial Marketing Management, $40,1238-1250$. 
Gomez, L. F. ve Ballard, D. I. (2013), "Communication for the Long Term: Information Allocation and Collective Reflexes as Dynamic Capabilities", Journal of Business Communication, 50 (2), 208-220.

Grant, R. M. (1991), "The Resource-Based Theory of Competitive Advantage: Implications for Strategy Formulation", California Management Review, 33 (3), 114-135.

Griffith, D. A. ve Harvey, M. (2001), "A Resource Perspective of Global Dynamic Capabities", Journal of International Business Studies, 32 (3), 597606.

Gümüşoğlu, L. (2012), "Dinamik Yeteneklerin Yeni Ürün Geliştirme Performansı Üzerine Etkileri: Farklı İş Stratejileri İçin Sonuçlar", İktisat İşletme ve Finans Dergisi, 27 (320), 61-90.

Helfat, C. (1997), "Know-how and Asset Complementarity and Dynamic Capability Accumulation: The Case of R \& D", Strategic Management Journal, 18, 339-360.

Helfat, C. ve Peteraf, M. (2003), "The Dynamic Reource Based View: Capability Lifecycles", Strategic Management Journal, 24, 997-1010.

Helfat, C., Finkelstein, S., Mitchell, W., Peteraf M., Singh H., Teece, D. ve Winter S. (2007), "Dynamic Capabilities Understanding Strategic Change in Organizations", 1. Bask1, ABD: Blackwell Publishing.

Hermano, V. ve Martín-Cruz, N. (2016), "The Role of Top Management Involvement in Firms Performing Projects: A Dynamic Capabilities Approach", Journal of Business Research,1-12.

Hodgkinson, G. P. ve Healey, M. P. (2011), "Psychological Foundations of Dynamic Capabilities: Reflexion and Reflection in Strategic Management", Strategic Management Journal, 32, 1500-1516.

Huang, K. F., Wu, L. Y., Dyerson, R. ve Chen C. F. (2012), "How does Technological Firm Develop Its Competitive Advantage? A Dynamic Capabilities Perspective", IEEE Transactions on Engineering Management, 59 (4), 644-652.

Iris, R. ve Vikas, A. (2011), "E-Learning Technologies: A Key to Dynamic Capabilities", Computers in Human Behavior, 27, 1868-1874.

Janssen, M. J., Castaldi C. ve Alexiev A. (2015), "Dynamic Capabilities for Service Innovation: Conceptualization and Measurement", $R \& D$ Management, $1-15$.

Jantunen, A., Ellonena, H. ve Johansson, A. (2012), "Beyond Appearances-Do Dynamic Capabilities of Innovative Firms Actually Differ", European Management Journal, 30, 141-155. 
Jiao, H., Alon I., Koo, C. K. ve Cui, Y. (2013), "The Moderating Effect of Enviromantal Dynamism Between Dynamic Capabilities and New Venture Performance", Journal of Engineering and Technology Management, 30, 188205.

Jones, O., Ghobadian, A., O'Regan, N. ve Antcliff, V. (2013), "Dynamic Capabilities in a Sixth-Generation Family Firm: Entrepreneurship and the Bibby Line", Business History, 55 (6), 910-940.

Karımı, J. ve Walter, Z. (2015), "The Role of Dynamic Capabilities in Responding to Digital Disruption: A Factor-Based Study of the Newspaper Industry", Journal of Management Information Systems, 32(1), 39-81.

Kay, N. (2007), "Dynamic Capabilities as Context: The Role of Decision, System and Structure", Dynamic Capabilities and Beyond Conference, 1-28.

Kim, G., Shin, B., Kim, K. K., ve Lee, H. G. (2011), "IT Capabilities, Process Oriented Dynamic Capabilities, and Firm Financial Performance", Journal of the Association for Information Systems, 12 (7), 487-517.

Kindström, D., Kowalkowski C. ve Sanberg E. (2013), "Enabling Service Innovation: A Dynamic Capabilities Approach", Journal of Business Research, 66, 1063-1073.

Kor, Y. ve Mesko, A. (2013), "Dynamic Managerial Capabilities: Configuration and Orchestration of Top Executives' Capabilities and the Firm's Dominant Logic", Strategic Management Journal, 34, 233-244.

Lawcon, B. ve Samson, D. (2001), "Developing Innovation Capability in Organizations: A Dynamic Capabilities Approach", International Journal of Innovation Management, 5 (3), 377-400.

Lee, P. Y., Kung, C. Y. ve Li C. S. J. (2015), "Developing Dynamic Capabilities in Culturally Distant Service Multi-Units", Industrial Management \& Data Systems, 115(8), 1547-1562.

Leung, R. C. (2012), "Health Information Technology and Dynamic Capabilities", Health Care Management Review, 37 (1), 43-53.

Leonidou, L. C., Leonidou, C. N., Fotiadis T. A. ve Aykol B. (2015), "Dynamic Capabilities Driving an Eco-Based Advantage and Performance in Global Hotel Chains: The Moderating Effect of International Strategy", Tourism Management, 50, 268-280.

Li, D. Y. ve Liu, J. (2012), "Dynamic Capabilities, Environmental Dynamism, and Competitive Advantage: Evidence from China", Journal of Business Research, 67 (1), 2793-2799. 
Lin Y. T., Chun H. C. ve Chuang S. H. (2015), "Explore the Development of Social Enterprises in Taiwan from the Dynamic Capabilities Approach", in 9th International Conference on Innovative Mobile and Internet Services in Ubiquitous Computing, 502-505.

Lin, C. C. ve Ma H. Y. (2014), "What Dynamic Capabilities are Needed in ERP Activity?", New Marketing Research Journal, 1-18.

Lin H. F., Su J. Q. ve Higgins A. (2016), "How Dynamic Capabilities Affect Adoption of Management Innovations", Journal of Business Research, 69, 862-876.

Luo, Y. (2000), "Dynamic Capabilities in International Expansion", Journal of World Business, 35 (4), 355-378.

Macpherson, A., Herbane B. ve Jones, O. (2015), "Developing Dynamic Capabilities through Resource Accretion: Expanding the Entrepreneurial Solution Space", Entrepreneurship \& Regional Development, 27 (5-6), 259291.

Makadok, R. (2001), "Toward a Synthesis of the Resource-Based and DynamicCapability Views of Rent Creation", Strategic Management Journal, 22 (5), 387-401.

Makkonen, H., Pohjolab, M., Olkkonena, R. ve Koponena, A. (2012), "Dynamic Capabilities and Firm Performance in a Financial Crisis", Journal of Business Research, 67 (1), 2707-2719.

Masteika I. ve Čepinskis J. (2015), "Organizational Dynamic Capabilities Impact on Changes in Supply Chain", Management Theory and Studies for Rural Business and Infrastructure Development, 37 (4), 541-551.

Naldi, L, Wikström, P. ve Rimscha M. B. V. (2014), "Dynamic Capabilities and Performance: An Empirical Study of Audiovisual Producers in Europe", International Studies of Management \& Organization, 44 (4), 63-82.

Narayanan, V., Colwell, K. ve Douglas F. L. (2009), "Building Organizational and Scientific Platforms in the Pharmaceutical Industry: A Process Perspective on the Development of Dynamic Capabilities", British Journal of Management, 20, 25-40.

Nelson, R. ve Winter S. (1982), "An Evolutionary Theory of Economic Change", 1. Bask1, ABD: Harvard College.

Newbert, S. L. (2007), "Empirical Research on the Resource-Based View of the Firm: An Assessment and Suggestions for Future Research", Strategic Management Journal, 28 (2), 121-146. 
Newey, L. R., Verreynne, M. L. ve Griffiths, A. (2012), "The Relationship between Dynamic and Oprerating Capabilities as a Stage-gate Process: Insights from Radical Innovation", Journal of Management \& Organization, 18 (1), 123-140.

Oliver, J. (2014), "Dynamic Capabilities and Superior Firm Performance in the UK Media Industry", Journal of Media Business Studies, 11(2), 57-77.

Olufemi O., Banjo H. A. ve Peter S. B. (2014), "Dynamic Capabilities and Competitive Advantage: An Analysis Of The Nigerian Banking Sector", Journal of Accounting and Management, 4 (2), 29-36.

Parente, R. C., Baack, D. W. ve Hahn E. D. (2011), "The Effect of Supply Chain İntegration, Modular Production, and Cultural Distance on New Product Development: A Dynamic Capabilities Approach", Journal of International Management, 17, 278-290.

Pavlou, P. A. ve Sawy, O. A. (2011), "Understanding the Elusive Black Box of Dynamic Capabilities", Decision Sciences, 42 (1), 239-273.

Penrose, E. (1959), "The Theory of the Growth of the Firm," 1,Bask1, Oxford: Blackwell Publishing.

Peteraf, M., Stefano G. ve Verona G. (2013), "The Elephant in the Room of Dynamic Capabilities: Bringing Two Diverging Conversations Together", Strategic Management Journal, 34 (12), 1389-1410.

Pezeshkan, A., Fainshmidt, S., Nair, A., Frazier, M. L. ve Markowski, E. (2016), "An Empirical Assessment of the Dynamic Capabilities-Performance Relationship", Journal of Business Research, 1-7.

Piening, E. P. (2013), "Dynamic Capabilities in Public Organizations", Public Management Review, 15 (2), 209-245.

Pitelis, C. ve Teece, D. (2010), "Cross-border Market Concretion, Dynamic Capabilities and the Entrepreneurial Theory", Industrial and Corporate Change, 19 (4), 1247-1270.

Prahaland C.K. ve Hamel G. (1990), "The Core Competence of the Corporation", Harvard Business Review, 79-91.

Priem R. L. ve Butler J. E. (2001), "Is the Resource-Based View a Useful Perspective for Strategic Management Research?", Academy of Management Review, 26 (1), 22-40.

Protogerou, A., Caloghirou, Y. ve Lioukas S. (2011), "Dynamic Capabilities and Their Indirect Impact on Firm Performance", Industrial and Corporate Change, 21 (3), 615-647. 
Ramirez, R., Riku Ö. ve, Daniel, G. (2013), "Scenarios and Early Warning as

Dynamic Capabilities to Frame Managerial Attention", Technological Forecasting \& Social Change, 80, 825-838.

Ravishankar, M. ve Pan, S. (2013), "Examining the Influence of Modularity and KM on Dynamic Capabilities: Insights from a Call Center", International Journal of Information Management, 33, 147-159.

Rice, J., Liao T. S., Galvin P. ve Martin N. (2015), "A Configuration-Based Approach to Integrating Dynamic Capabilities and Market Transformation in Small and Medium-Sized Enterprises to Achieve Firm Performance", International Small Business Journal, 33(3), 231-253.

Rindova, V. ve Kotha, S. (2001), "Continuous Morphing: Competing through Dynamic Capabilities, Form, and Function", Academy of Management Journal, 44 (6), 1263-1280.

Rodenbach, M. ve Brettel, M. (2012), "CEO Experience as Micro-level Origin of Dynamic Capabilities", Management Decision, 50 (4), 611-634.

Russo, M. (2009), "Explaining the Impact of ISO 14001 on Emission Performance: A Dynamic Capabilities Perspective on Process and Learning", Business Strategy and the Environment, 18 (5), 307-319.

Salunke, S., Weerawardena, J. ve McColl-Kennedy J. R. (2011), "Towards a Model of Dynamic Capabilities in Innovation-based Competitive Strategy", Industrial Marketing Management, 40, 1251-1263.

Schilke, O. (2013), "On the Contingent Value of Dynamic Capabilities for Competitive Advantage: The Nonlinear Moderating Effect of Environmental Dynamism", Strategic Management Journal, 35 (2), 179-203.

Schilke, O. (2014), "Second-Order Dynamic Capabilities: How Do They Matter?", The Academy of Management Perspectives, 28 (4), 368-380.

Schreyögg, G. ve Kliesch-Eberl, M. (2007), "How Dynamic Can Organizational Capabilities be? Towards a Dual Process Model of Capability Dynamization", Strategic Management Journal, 28, 913-933.

Sicotte, H., Drouin N. ve Delerue H. (2014), "Innovation Portfolio Management as a Subset of Dynamic Capabilities: Measurement and Impact on Innovative Performance", Project Management Journal, 45(6), 58-72.

Stefano, G. D., Peteraf M. ve Verona G. (2014), "The Organizational Drivetrain: A Road to Integration of Dynamic Capabilities Research", The Academy of Management Perspectives, 28 (4), 307-327.

Süslüoğlu, M. (2012), "Işsletmelerde Çekirdek Teknolojilerle Dinamik Yeteneklerin Arasındaki Işbirliğinin Dĕgerlendirilmesi", http://mehmetsusluoglu.blogspot.com.tr/search/label/dinamik\%20yetenek. 
Şahin K., Mert K., Kaplan T. (2015), "Global Dinamik Yeteneklerin Uluslararasılaşma Sürecinde Kullanımı: İşletme Grupları Perspektifi", Ankara Üniversitesi SBF Dergisi, 70, 931-956.

Takahashi A. R. W., Bulgacov S., Giacomini M. M. ve Santos C. B. D. (2016), "Dynamic Capabilities, Political External Relationship, Educational Technology Capability and Firm Performance", International Business Management, 10 (5), 652-658.

Teece, D. ve Pisano, G. (1994), "The Dynamic Capabilities of Firms: An Introduction", Industrial and Corporate Change, 3 (3), 537-556.

Teece, D., Pisano, G. ve Shuen, A. (1997), "Dynamic Capabilities and Strategic Management", Strategic Management Journal, 18(7), 509-533.

Teece, D. (2003), "Essays in Technology Management and Policy", 1. Bask1, USA: World Scientific Publishing Co.

Teece, D. (2007), "Explicating Dynamic Capabilities: The Nature and Microfoundations of Sustainable Enterprise Performance", Strategic Management Journal, 28 (13), 1319-1350.

Teece, D. (2009), "Dynamic Capabilities and Strategic Management", 1, Bask1, New York: Oxford University Press.

Teece, D. (2012), "Dynamic Capabilities: Routines versus Entrepreneurial Action", Journal of Management Studies, 49 (8), 1395-1401.

Ünsal, E. (2009), "Dinamik Bir Yetenek Olarak Teknoloji Yönetimi: Teknoloji Yönetimi Yeteneği", Kara Harp Okulu Savunma Bilimleri Enstitüsü Dergisi, $82(8), 167-189$.

Vanpoucke E., Vereecke A. ve Wetzels M. (2014), "Developing Supplier Integration Capabilities for Sustainable Competitive Advantage: A Dynamic Capabilities Approach", Journal of Operations Management, 32, 446-461.

Wang, C. ve Ahmed, P. (2007), "Dynamic Capabilities: A Review and Research Agenda", International Journal of Management Reviews, 9(1), 31-51.

Wernerfelt, B. (1984), "A Resource-based View of the Firm", Strategic Management Journal, 5(2), 171-180.

Wang C. L. Senaratne C.ve Rafiq M. (2015), "Success Traps, Dynamic Capabilities and Firm Performance", British Journal of Management, 26, 2644.

Weerawardena, J., Mort G. S., Salunke S., Knight G. ve Liesch P. W. (2015), "The Role Of The Market Sub-System And The Socio-Technical Sub-System In Innovation And Firm Performance: A Dynamic Capabilities Approach", Journal of the Academy of Marketing Science, 43, 221-239. 
Wernerfelt, B. (1995),"The Resource-based View of the Firm: Ten Years After", Strategic Management Journal, 16, 171-174.

Wilden, R., Gudergan, S. P., Nielsen, B. B. ve Lings, I. (2013), "Dynamic Capabilities and Performance: Strategy, Structure and Environment", Long Range Planning, 46, 72-96.

Winter, S. (2003), "Understanding Dynamic Capabilities", Strategic Management Journal, 24, 991-995.

Wilden, R. ve Gudergan S. P. (2015), "The Impact of Dynamic Capabilities on Operational Marketing and Technological Capabilities: Investigating the Role of Environmental Turbulence", Journal of the Academy of Marketing Science, 43, 181-199.

Wilhelm H., Schlömer, M. ve Maurer I. (2015), "How Dynamic Capabilities Affect the Effectiveness and Efficiency of Operating Routines under High and Low Levels of Environmental Dynamism", British Journal of Management, $26,327-345$.

Woldesenbet, K., Ram, M. ve Jones T. (2011), "Supplying Large Firms: The Role of Entrepreneurial and Dynamic Capabilities in Small Businesses", International Small Business Journal, 30(5), 493-512.

Wu, I. L. ve Hu, Y. P. (2012), "A Dynamic Capability View and the Mediating Role of Process Capability: A Dynamic Capability View and the Mediating Role of Process Capability", Journal of the Association for Information Systems, 13(12), 976-999.

Wu, L. Y. (2007), "Entrepreneurial Resources, Dynamic Capabilities and Start-up Performance of Taiwan's Hightech Firms", Journal of Business Research, 60, 549-555.

Wu, L. Y. (2010), "Applicability of the Resource-based and Dynamic Capability Views under Enviromental Volatility", Journal of Business Research, 63, 2731.

Wu, Q., He Q. ve Duan Y., (2014), "Dynamic Capabilities for CSR Management: Towards Identifying Common Processes", Society and Business Review, 9 (3), $276-297$.

Yamen, M. (2010), "Dinamik Yetenekler", http://www.belgeler.com/blg/2hlu/dinamik-yetenekler.

Yung, I. S. ve Lai, M. H. (2012), "Dynamic Capabilities in New Product Development: The Case of Asus in Motherboard Production," Total Quality Management, 23 (10), 1125-1134.

Yung, K. (2013), "Learning Orientation, Dynamic Capabilities and Performance in Korean High-tech Ventures", Advances in Management, 6(4), 54-61. 
Yusr, M., Othman, A. R. ve Mokhtar S. S. M. (2012), "Assessing the Mediating Role of Marketing Capability in the Relationship between TQM Practices and Innovation Performance Dynamic Capabilities Approach", International Journal of Business and Social Science, 3(23), 165-176.

Zahra, S. ve George, G. (2002), "Absorptive Capacity: A Review, Reconceptualization, and Extension", The Academy of Management Review, 27 (2), 185-203.

Zahra, S., Harry J. S. ve Per D. (2006), "Entrepreneurship and Dynamic Capabilities: A Review, Model and Research Agenda", Journal of Management Studies, 43(4), 917-955.

Zhan, W. ve Chen, R. (2013), "Dynamic Capabilities and IJV Performance: The Effect of Exploitation and Exploration Capabilities", Asia Pacific Journal of Management, 30, 601-632.

Zhou, K. ve Li, C. (2010), "How Strategic Orientations Influence the Building of Dynamic Capability in Emerging Economies", Journal Business Research, 63, 224-231.

Zollo, M. ve Winter, S. (1999), "From Organizational Routines to Dynamic Capabilities", Working Paper, The Wharton School: University of Pennsylvania.

Zollo, M. ve Winter, S. (2002), "Deliberate Learning and the Evolution of Dynamic Capabilities", Organization Science, 13 (3), 339-351. 